\title{
Hubungan Pengetahuan terhadap Tingkat Kepatuhan Pasien Tuberkulosis Paru di Puskesmas Binangun Cilacap
}

\author{
Vena Mellyana*1, Eva Nurinda ${ }^{1}$, Rizal Fauzi ${ }^{1}$, Sofyan Indrayana ${ }^{2}$ \\ ${ }^{1}$ Program Studi Sarjana Farmasi, Fakultas IImu-IImu Kesehatan, Universitas Alma Ata \\ ${ }^{2}$ Program Studi Sarjana IImu Keperawatan, Fakultas IImu-IImu Kesehatan, Universitas Alma Ata \\ Email : venamellyana48@gmail.com, evanurinda@almaata.ac.id, rizalfauzi@almaata.ac.id, \\ sofyan@almaata.ac.id \\ Korespondensi: \\ Vena Mellyana \\ Program Studi Sarjana Farmasi, Fakultas IImu-IImu Kesehatan, Universitas Alma Ata \\ venamellyana48@gmail.com
}

\begin{abstract}
Abstrak
Tuberkulosis merupakan penyakit menular yang disebabkan oleh bakteri Mycobacterium tuberkulosis. Tingkat keberhasilan pengobatan tuberkulosis sangat tergantung dari tingkat kepatuhan pasien. Pengetahuan merupakan salah satu faktor yang dapat mempengaruhi tingkat kepatuhan seseorang dalam menjalani tahap pengobatan. Pengetahuan pasien tentang penyebab, tanda dan gejala, penularan, pencegahan cara konsumsi dan lamanya pengobatan. Penelitian ini bertujuan untuk mengetahui hubungan pengetahuan terhadap tingkat kepatuhan pasien tuberkulosis paru di Puskesmas Binangun Cilacap. Jenis penelitian bersifat kuantitatif dengan pendekatan cross sectional. Teknik pengambilan sampel penelitian ini yaitu purposive sampling dengan populasi penelitian yaitu pasien yang sedang menjalani pengobatan tuberkulosis paru di Puskesmas Binangun Cilacap. Jumlah sampel penelitian sebanyak 32 respoden. Hasil penelitian menunjukan bahwa responden dengan tingkat kepatuhan tinggi sebanyak 29 orang $(90,6 \%)$. Responden dengan tingkat kepatuhan sedang sebanyak 3 orang $(9,4 \%)$. Responden dengan pengetahuan dan tingkat kepatuhan tinggi sebanyak 19 orang $(59,4 \%)$ dan responden dengan pengetahuan sedang dan tingkat kepatuhan tinggi sebanyak 10 orang $(31,3 \%)$ sedangkan respoden dengan pengetahuan dan tingkat kepatuhan sedang sebanyak 3 orang $(9,4 \%)$. Kesimpulan penelitian berdasarkan uji Spearman Rho diperoleh $p$-value $0,028<\alpha(0,05)$ dan $\tau 0,389$ sehingga dapat diketahui bahwa terdapat hubungan lemah antara pengetahuan dengan tingkat kepatuhan pasien tuberkulosis paru di Puskesmas Binangun Cilacap yang bersifat positif.
\end{abstract}

Kata Kunci: antituberculosis; pengetahuan; tingkat kepatuhan; tuberkulosis paru

INPHARNMED Journal, Vol.5, No.2, Tahun 2021, 1-7

Available from: http://ejournal.almaata.ac.id/index.php/INPHARNMED 


\title{
RELATIONSHIP OF KNOWLEDGE ON COMPLIANCE LEVEL OF PATIENTS WITH LUNG TUBERCULOSIS AT PUSKESMAS BINANGUN CILACAP
}

\begin{abstract}
Tuberculosis is an infectious disease caused by the bacteria Mycobacterium tuberculosis. The success rate of tuberculosis treatment depends on the level of patient compliance. Knowledge is one of the factors that can affect a person's level of adherence in undergoing the treatment stage. Patient's knowledge of causes, signs and symptoms, transmission, prevention of consumption and duration of treatment. This study aims to determine the relationship between knowledge and compliance levels of pulmonary tuberculosis patients at Binangun Cilacap Health Center. This type of research is quantitative with a cross sectional approach. The sampling technique for this research was purposive sampling with the population of the study, namely patients who were undergoing treatment for pulmonary tuberculosis at the Binangun Cilacap Health Center. The number of research samples was 32 respondents. The results showed that respondents with a high level of compliance were 29 people (90.6\%). Respondents with moderate level of compliance were 3 people (9.4\%). Respondents with high knowledge and compliance levels were 19 people (59.4\%) and respondents with moderate knowledge and high levels of compliance were 10 people (31.3\%) while respondents with moderate knowledge and compliance levels were 3 people (9.4\%)). The conclusion of the study based on the Spearman Rho test obtained a p-value of $0.028<\alpha(0.05)$ and $\tau 0.389$, so it could be seen that there was a weak relationship between knowledge and the level of compliance of pulmonary tuberculosis patients at Binangun Cilacap Community Health Center which is positive.
\end{abstract}

Keywords: antitubercular medications; knowledge, compliance level, tuberculosis

Received: 10 Agustus 2021

Accepted: 13 Desember 2021

\section{PENDAHULUAN}

Tuberkulosis (TB) merupakan penyakit menular yang disebabkan oleh bakteri Mycobacterium tuberkulosis yang sebagian besar menyerang paru-paru ${ }^{1}$, namun juga dapat menyerang organ tubuh lainnya seperti selaput otak, kelenjar getah bening, kelenjar limfe, ginjal, pleura, telinga bagian tengah, usus, tulang belakang, tenggorokan mata dan kulit ${ }^{2}$. Pengetahuan yang dimiliki pasien menjadi salah satu faktor yang dapat mempengaruhi terjadinya kegagalan terapi selain peran pengawas minum obat, dukungan keluarga, akses transportasi dan jarak dari tempat tinggal pasien menuju tempat pelayanan kesehatan, motivasi dan efek samping yang dirasakan ${ }^{3,4}$. 
Kepatuhan diartikan sebagai tingkatan seseorang dalam berperilaku untuk memperoleh keberhasilan pengobatan, diet dan melakukan gaya hidup yang sesuai dengan rekomendasi dari pelayanan kesehatan ${ }^{5,6}$. Kepatuhan merupakan suatu gambaran perilaku yang terbentuk karena adanya interaksi dari petugas kesehatan dengan penerima terapi atau pasien agar pasien dapat mengerti rencana dan konsekuensi dari langkah yang diambil serta menyetujui hasil perencanaan dan melaksanakannya ${ }^{7,8}$. Kepatuhan merupakan suatu gambaran perilaku yang terbentuk karena adanya interaksi dari petugas kesehatan dengan penerima terapi atau pasien agar pasien dapat mengerti rencana dan konsekuensi dari langkah yang diambil serta menyetujui hasil perencanaan dan melaksanakannya9.

\section{METODE PENELITIAN}

\section{Bahan dan Metode}

Penelitian ini dilakukan di Puskesmas Binangun Cilacap dan mulai dilakukan pada 15 Juni sampai 24 Juli 2020. Populasi dari sasaran penelitian yaitu pasien yang sedang menjalani pengobatan tuberkulosis (TB) paru di Puskesmas Binangun Cilacap berjumlah 34 responden. Teknik sampling dari penelitian ini yaitu purposive sampling. Jumlah sampel 32 respoden yang diperoleh dari rumus Slovin ${ }^{10}$.

\section{Rancangan Penelitian}

Jenis penelitian ini adalah kuantitatif dengan pendekatan cross sectional dimana pengetahuan dan kepatuhan pasien dinilai secara bersamaan dengan menggunakan kuesioner.

\section{HASIL DAN PEMBAHASAN}

\section{Karakteristik Data Pasien}

Berdasarkan hasil penelitian yang telah dilakukan terhadap 32 responden. Karakteristrik responden dalam penelitian meliputi usia, jenis kelamin, pendidikan, pekerjaan dan tahap pengobatan didapatkan hasil sebagai berikut: 
Tabel 1. Distribusi Frekuensi Karakteristik Responden

\begin{tabular}{llcccccc}
\hline Karakteristrik & \multicolumn{1}{c}{ Kategori } & N=32 & (\%) & Min & Max & Mean & SD \\
\hline Usia & 17-25 tahun & 11 & 34,4 & 19 & 62 & 33,63 & 11,867 \\
& 26-35 tahun & 10 & 31,3 & & & & \\
& 36-45 tahun & 6 & 18,8 & & & & \\
& 46-55 tahun & 4 & 12,5 & & & & \\
Jenis Kelamin & 56-65 tahun & 1 & 3,1 & & & & \\
& Laki-laki & 13 & 40,6 & 1 & 2 & 1,59 & 0,499 \\
Pendidikan & Perempuan & 19 & 59,4 & & & & \\
& SD atau sederajat & 5 & 15,6 & 2 & 4 & 3,47 & 0,761 \\
& SMP atau sederajat & 7 & 21,9 & & & & \\
Pekerjaan & SMA atau sederajat & 20 & 62,5 & & & & \\
& Pelajar & 4 & 12,5 & 1 & 4 & 2,63 & 1,008 \\
& Petani & 12 & 37,5 & & & & \\
Tahap & Buruh & 8 & 25,0 & & & & \\
Pengobatan & IRT & 8 & 25,0 & & & & \\
\hline Total & Lanjutan & 3 & 9,4 & 1 & 2 & 1,09 & 0,296 \\
\hline
\end{tabular}

Berdasarkan Tabel 1 diketahui bahwa karakteristik responden sebagian besar berada pada rentang usia 17-25 tahun sebanyak 11 orang atau 34,4\%, jenis kelamin responden didominasi oleh perempuan sebanyak 19 orang atau 59,4\%, pendidikan terakhir SMA atau sederajat sebanyak 20 responden atau 62,5\%, mayoritas responden bekerja sebagai petani sebanyak 12 orang atau 37,5\%, dan sebagian besar responden berada di tahap pengobatan lanjutan sebanyak 29 orang atau 90,6\%.

Tabel 2 Distribusi Frekuensi Pengetahuan dan Tingkat Kepatuhan Pasien Tuberkulosis Paru

\begin{tabular}{llcccccc}
\hline Karakteristrik & Kategori & $\mathbf{N = 3 2}$ & $\mathbf{( \% )}$ & Min & Max & Mean & SD \\
\hline Pengetahuan & Tinggi & 19 & 59,4 & 56 & 100 & 79,69 & 10,427 \\
& Sedang & 13 & 40,6 & & & & \\
Tingkat & Tinggi & 29 & 90,6 & 80 & 100 & 95,00 & 6,720 \\
Kepatuhan & Sedang & 3 & 9,4 & & & & \\
\hline & Total & $\mathbf{3 2}$ & $\mathbf{1 0 0}$ & & & & \\
\hline
\end{tabular}

Berdasarkan Tabel 2 diketahui responden yang menjalani pengobatan tuberkulosis paru mempunyai pengetahuan tinggi sebanyak 19 responden atau 59,4\% dan tingkat kepatuhan yang tinggi yaitu sebanyak 29 responden atau sebesar 90,6\%. Berdasarkan Tabel 3 menunjukan mayoritas responden dengan pengetahuan dan tingkat pengetahuan tinggi sebanyak 19 orang atau 59,4\%. Responden dengan pengetahuan sedang mayoritas mempunyai tingkat pengetahuan yang tinggi sebanyak 10 orang atau 31,3\%. Hasil perhitungan statistik menggunakan uji Spearman Rho diperoleh $p$-value sebesar 0,028< 
$\alpha(0,05)$ sehingga dapat diketahui bahwa terdapat hubungan antara pengetahuan dengan tingkat kepatuhan pasien tuberkulosis paru di Puskesmas Binangun Cilacap. Nilai koefisien korelasi positif $\tau$ 0,389 menunjukan bentuk hubungan searah yang berarti semakin tinggi pengetahuan yang dimiliki pasien tuberkulosis paru maka semakin tinggi pula tingkat kepatuhan minum obat pasien akan semakin baik.

Tabel 3. Hasil Analisis Tabulasi Silang Hubungan Pengetahuan dengan Tingkat Kepatuhan Pasien Tuberkulosis Paru di Puskesmas Binangun Cilacap

\begin{tabular}{|c|c|c|c|c|c|c|c|c|}
\hline \multirow{3}{*}{ Pengetahuan } & \multicolumn{4}{|c|}{ Tingkat Kepatuhan } & \multirow{2}{*}{\multicolumn{2}{|c|}{ Total }} & \multirow{3}{*}{$\tau$} & \multirow{3}{*}{$p$-value } \\
\hline & \multicolumn{2}{|c|}{ Tinggi } & \multicolumn{2}{|c|}{ Sedang } & & & & \\
\hline & $\mathrm{N}$ & $\%$ & $\mathrm{n}$ & $\%$ & $\mathrm{~N}$ & $\%$ & & \\
\hline Tinggi & 19 & 59,4 & 0 & 0,0 & 19 & 59,4 & & \\
\hline Sedang & 10 & 31,3 & 3 & 9,4 & 13 & 40,6 & 0,389 & 0,028 \\
\hline Total & 29 & 90,6 & 3 & 9,4 & 32 & 100 & & \\
\hline
\end{tabular}

Hasil penelitian ini didukung penelitian terdahulu bahwa pegetahuan berpengaruh secara signifikan dengan tingkat kepatuhan pasien dalam menjalani pengobatan tuberkulosis paru ${ }^{11,12}$. Penelitian ini sejalan dengan penelitian yang dilakukan oleh Arini (2016) yang menyatakan bahwa antara pengetahuan dengan tingkat kepatuhan mempunyai korelasi yang lemah namun searah ${ }^{13}$. Hasil penelitian sesuai dengan laporan hasil pengamatan di lapangan bahwa kurangnya pengetahuan dapat meningkatkan angka kejadian penyakit tuberkulosis paru ${ }^{14,15}$. Pengetahuan merupakan salah satu faktor yang mempengaruhi kepatuhan pasien tuberkulosis ${ }^{16,17}$.

Kepatuhan minum obat yang tinggi dalam menjalani tahapan pengobatan memberikan dampak positif dengan meningkatkan angka kesembuhan, angka kematian dan persentase kekambuhan tuberkulosis menurun, serta meminimalkan terjadinya multi drug resistence atau resistensi dari kuman terhadap obat anti tuberkulosis tertentu sehingga penyakit tuberkulosis akan mudah disembuhkan dengan pengobatan yang rutin. Kepatuhan menjadi salah satu faktor peningkat kesembuhan tuberkulosis.

\section{KESIMPULAN DAN SARAN}

Berdasarkan penelitian yang telah dilakukan dapat disimpulkan bahwa terdapat hubungan antara pengetahuan dengan kepatuhan pasien tuberkulosis paru yang menjalani pengobatan di Puskesmas Binangun Cilacap. Semakin baik pengatahuan pasien 
terkait dengan pengobatannya maka semakin tinggi kepatuhannya dalam minum obat antituberkulosis.

Hasil penelitian ini dapat menjadi rujukan penelitian selanjutnya untuk mengetahui faktor utama yang mempengaruhi pengetahuan dan kepatuhan pasien dalam mengkonsumsi obat. Selain itu, peran farmasis dalam memberikan intervensi secara kolaborasi multidisiplin untuk meningkatkan kualitas hidup dan keberhasilan terapi pasien dengan tuberkulosis paru perlu untuk dilakukan.

\section{KONFLIK KEPENTINGAN}

Seluruh penulis menyatakan tidak terdapat potensi konflik kepentingan dengan penelitian dan atau publikasi artikel ini.

\section{DAFTAR PUSTAKA}

1. Kemenkes RI. Profil Dinas Kesehatan Kota Surabaya. Tahun 2016. Dinas Kesehatan. Jakarta: Kementrian Kesehatan RI; 2016. 19-20 p.

2. Chin J. Manual Pemberantasan Penyakit Menular. Edisi 17. Kandun IN, editor. Jakarta: Informedika; 2000. 543 p.

3. Mientarini El, Sudarmanto Y, Hasan M. Hubungan Pengetahuan Dan Sikap Terhadap Kepatuhan Minum Obat Pasien Tuberkulosis Paru Fase Lanjutan Di Kecamatan Umbulsari Jember. Ikesma. 2018;14(1):11.

4. Nurbaety B, Wahid AR, Suryaningsih E. Gambaran Tingkat Pengetahuan dan Kepatuhan Pada Pasien Tuberkulosis di Rumah Sakit Umum Provinsi NTB Periode JuliAgustus 2019. Lumbung Farm J Ilmu Kefarmasian. 2020;1(1):8.

5. Kemenkes RI. Pedoman Nasional Pengendalian Tuberkulosis. Kementeri Kesehat Republik Indones. 2014;(Pengendalian Tuberkulosis):110.

6. Fekadu G, Bekele F, Bekele K, Girma T, Mosisa G, Gebre M, et al. Adherence to antituberculosis treatment among pediatric patients at nekemte specialized hospital, Western Ethiopia. Patient Prefer Adherence. 2020;14:1259-65.

7. Nezenega ZS, Perimal-lewis L, Maeder AJ. Factors influencing patient adherence to tuberculosis treatment in ethiopia: A literature review. Int J Environ Res Public Health. 2020;17(15):1-12.

8. Pradipta IS, Houtsma D, van Boven JFM, Alffenaar JWC, Hak E. Interventions to improve medication adherence in tuberculosis patients: a systematic review of randomized controlled studies. npj Prim Care Respir Med [Internet]. 2020;30(1). Available from: http://dx.doi.org/10.1038/s41533-020-0179-x

9. Panesar K. Patient Compliance and Health Behavior Models. US Pharm. 2012;37(4):12-4.

10. Sugiyono P. Metode Penelitian Kuantitatif Kualitatif dan R\&D. Bandung: Alpabeta; 2011. $87 \mathrm{p}$. 
11. Hendesa A, Tjekyan RMS, Pariyana. Hubungan Pengetahuan, Sikap, Dan Dukungan Keluarga Dengan Kepatuhan Berobat Pada Pasien Tuberkulosis Paru Di Rs Paru Kota Palembang Tahun 2017. Maj Kedokt Sriwij [Internet]. 2018;4(Oktober):175-84. Available from: https://ejournal.unsri.ac.id/index.php/mks/article/view/8565

12. Nimah L, Sartika R, Makhfudli . Family Knowledge and Attitudes to Improve Medication Adherence in Patients with Pulmonary Tuberculosis. Proc 9th Int Nurs Conf. 2019;(International Nursing Conference (INC 2018)):29-32.

13. Ariyani H. Hubungan Tingkat Pengetahuan Dengan Kepatuhan Pada Pengobatan Penderita Tuberkulosis Paru di Puskesmas Pekauman Kota Banjarmasin, Kalimantan Selatan. J Pharmascience [Internet]. 2016;03(02):23-8. Available from: https://ppjp.ulm.ac.id/journal/index.php/pharmascience/article/view/5734/4797

14. Putera I, Pakasi TA, Karyadi E. Knowledge and perception of tuberculosis and the risk to become treatment default among newly diagnosed pulmonary tuberculosis patients treated in primary health care, East Nusa Tenggara: A retrospective study. BMC Res Notes. 2015;8(1):4-9.

15. Kigozi NG, Heunis JC, Engelbrecht MC, Janse Van Rensburg AP, Van Rensburg HCJD. Tuberculosis knowledge, attitudes and practices of patients at primary health care facilities in a South African metropolitan: Research towards improved health education. BMC Public Health. 2017;17(1):1-8.

16. Sariem CN, Nanlir ZS, Banwat SB, Dapar MP. Factors influencing tuberculosis medication adherence : A cognitive intervention in a resource limited setting. World J Pharm Sci [Internet]. 2015;3(9):1912-20. Available from: www.wjpsonline.org/ download.php

17. Hidayat J, Lee M-C, Lee M-D, Chen C-H. The Relationship between Knowledge and Medication Compliance Behavior among Patients with Tuberculosis. South East Asia Nurs Res. 2020;2(2):1. 